\title{
Assessment of slopes endangered by groundwater
}

\author{
P. P. Prochazka ${ }^{1} \&$ J. Trckova ${ }^{2}$ \\ ${ }^{1}$ Czech Technical University Prague, Czech Republic \\ ${ }^{2}$ Academy of Sciences, Prague, Czech Republic
}

\begin{abstract}
In many cases of deposits like tailings from open pit mines, the environment is damaged by the long extension of the slopes. Steeper slopes have a better influence on the landscape. On the other hand, the basic problem is caused by ground water, which a posteriori, after completing the construction of these structures, seeps through the foundation of the slopes. It is very important that no reclaim helps to solve this problem. If the deposits are founded in the wrong way, i.e. in the foundations where no disturbances of capillary water are applied, new methods have to be employed in order to stabilize the slopes. Before this, studies concerning the influence of ground water on the slope stability of the deposits have to be carried out. Natural slopes cannot practically be assessed, as the expanses involved in such tests are enormous. This is why scale models are prepared, together with numerical analysis based on coupled modeling. The influence of water is simulated by free internal parameters, which describe the extent of the hydration. On the other hand, geotechnical parameters change according to rules determined in the laboratory. Such a complex discussion can then be a starting point for several improvements of the slopes. The coupled modeling (scale and numerical) is applied to prepare a parametric study of tailing dams in Northern Bohemia, where large problems occurred because of the moving of current slopes against existing villages in this region. Scale models have been created in compliance with real situations and the results from them implemented in mathematical models. A parametric study was carried out using the numerical models.
\end{abstract}

Keywords: tailing dams, Desai's distinct state model, scale modeling, numerical modeling, coupled modeling. 


\section{Introduction}

In Northern Bohemia a problem occurs as a result of poor foundations of tailing dams from open pit mines. They move towards existing villages, in some cases at a rate of $1 \mathrm{~cm}$ a day. The villages are threatened by the moving mass of slopes of very high ridge. The solution to this situation is based on mathematical modeling, which has to be adjusted by comparing results from scale modeling and numerical results. Here, Desai's model [1] of the watering of underground mass is used together with eigenparameters, serving as the design parameters for an optimization problem (actually, smart back analysis is introduced). In [2], the optimal material properties of slopes are sought using similar techniques. An approach considering both scale and numerical modeling is sometimes called coupled modeling. This is widely used in some preceding papers by the authors of this paper, [3-5]. Deposits and tailing dams are also solved in these papers for different real-life cases, but in these papers the influence of water is not considered, which is obviously the most dangerous phenomenon. Now, we have a large scale of tests available, which also covers the response of the slope material to the effect of wetting the slope mass. The aim of this paper is to show an approach, which leads to a very good numerical model for being able to assess different defence technologies against moving deposits.

\section{Deformation of the deposit due to underflooding}

Deformation of deposits caused by water levels that increase to reach the toe of the deposit slope have been observed on scale models of physically equivalent materials. The models were created as a dam; $10 \mathrm{~m}$ high, $15 \mathrm{~m}$ wide and with a slope of $30^{\circ}$. The models were prepared in a modeling stand, which is a basin $800 \times 230 \times 600 \mathrm{~mm}^{3}$ (length $\times$ width $\times$ height $)$, created in a stiff steel frame, in which waterproofed Plexiglas walls of a thickness of $12 \mathrm{~mm}$ are fastened. The scale of the dimensions of the real:model slope are 1:100.

Measurement points are placed on the surface of the model and in the longitudinal axis, (fig. 1). At measurement points in each stage of the level of groundwater, movement at these points was identified using theodolit, which assesses vertical and horizontal angles $\alpha_{\mathrm{i}}$ and $\beta_{\mathrm{i}}$. Knowing the distance $\mathrm{d}$ of the axis of theodolit from the measurement points, and with known changes of vertical and horizontal angles in each consecutive stage of water level, the vectors of movements $\mathrm{v}_{\mathrm{i}}$ at distinct measurement points are calculated as:

$$
a_{i}=\text { d.tg }\left(\alpha_{i}-\alpha_{i-1}\right), \quad b_{i}=d \cdot \operatorname{tg}\left(\beta_{i^{-}} \beta_{i-1}\right), \quad v_{i}=\sqrt{a_{i}^{2}+b_{i}^{2}} .
$$

Water was fed into the model through openings at the base of the stand through hoses connected to a water reservoir. From this reservoir the water was added to the stand according to the requirements of the simulated process. After each increase in water level, photos of the situation in the stands and measurements at measurement points documented the status of the sample. 


\subsection{Physical model 2023}

The first of the models was created from a mixture of very fine balotine, $89,98 \%$, ferrosilicia $10 \%$, and a fat A00 $0,02 \%$. This material in the selected scale reasonably simulates stiffened sand soils, which are predisposed to low swelling.

The physical and mechanical properties of the modeled material in a naturally moistened state are defined as:

$\begin{array}{ll}\text { Volume weight } \rho & 1.93 \mathrm{~g} / \mathrm{cm}^{3} \\ \text { Tensile strength } \sigma_{\mathrm{c}} & 6.9 \mathrm{kPa} \\ \text { Cohesion (triaxial) c } & 5.9 \mathrm{kPa} \\ \text { Angle of int. friction } \varphi & 15^{\circ} \\ \text { Young's modulus E } & 2.1 \mathrm{MPa} \\ \text { Oedometric modulus of deformation } \mathrm{E}_{\mathrm{u}} & 0.5 \mathrm{MPa} \\ \text { Coefficient of compressibility C } & 54.6 \\ \text { Poisson's number } v & 0.33\end{array}$

Material with an extremely low volume swelling of $1.3 \%$ was prepared. After completing the scale models, the water was allowed into the stands. In figs. 2a and $2 \mathrm{~b}$, the states before wetting and after the final stage of wetting are depicted. In Table 1, the vectors of displacements at the measurement points are introduced for entire flow of the test. Changes of horizontal $x$ and vertical $y$ displacements, together with the resultant vector $d$ are there shown. The minus sign denotes right and downwards. Values are given in $\mathrm{mm}$.

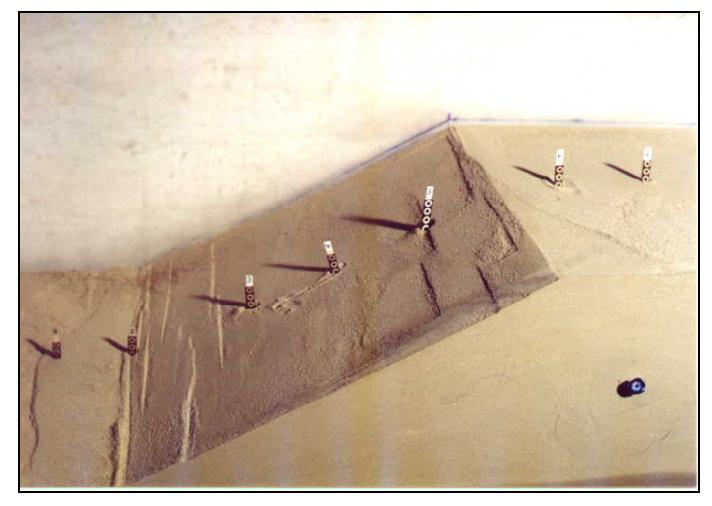

Figure 1: Measurement points.

The test was divided into several stages depending on the height of the water level in the stand. In the first stage, no water takes place in the sample. The displacements in the second stage also involve movements due to the imprecise settlement of the equivalent material around the drainage hose, the water was let into the stand, which is why the values are not introduced in tables. At the third stage, when the water level reached $9.5 \mathrm{~cm}$ and the fourth stage (water level at $21 \mathrm{~cm}$ above the bottom of the stand), the movements were relatively small. The 
decisive displacements were registered in the stages when the water started to approach the toe of the slope and seepage into the slope began to take place (stages $5-6$ ).

a)

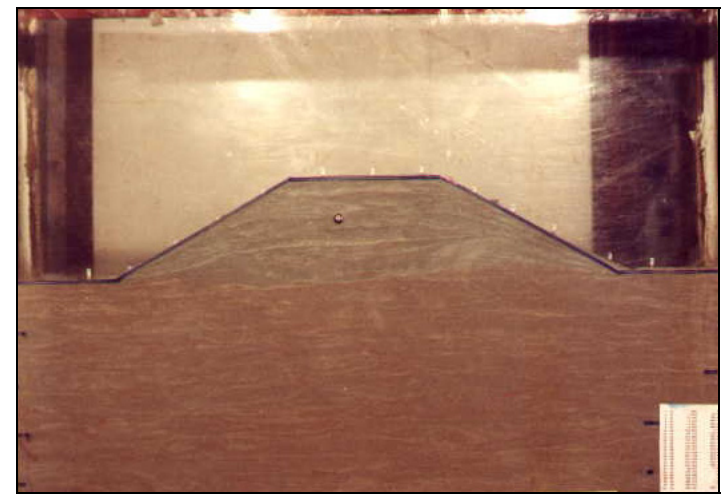

b)

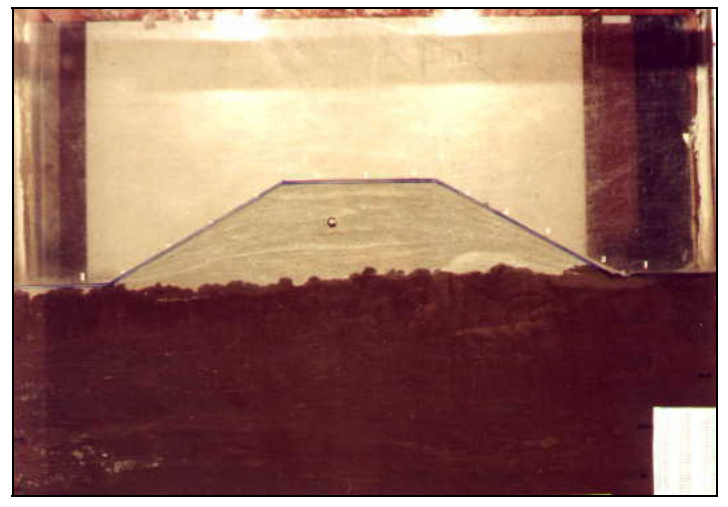

Figure 2: Photo of model 2023 before water was let in, a), and after end of the test, b).

After completing the test, selected material coefficients were tested in the laboratory to obtain information on how material properties changed from before and after water saturation of the soil and checked with the results of the numerical model proposed.

\subsection{Physical model 2024}

The material for the second test was created from slightly different components. The physical and mechanical properties of the modeled material in a naturally moistened state are defined as follows:
Volume weight $\rho$
$1.93 \mathrm{~g} / \mathrm{cm}^{3}$
Tensile strength $\sigma_{\mathrm{c}}$
$8.8 \mathrm{kPa}$
Cohesion (triaxial) c
$7.9 \mathrm{kPa}$ 
Table 1: $\quad$ Horizontal $\mathrm{x}$, vertical $\mathrm{y}$, and resultant displacements d.

\begin{tabular}{|c|c|c|c|c|c|c|c|c|c|}
\hline \multirow{2}{*}{ Point } & \multicolumn{3}{|c|}{ Stage 1 } & \multicolumn{3}{c|}{ Stage 4 } & \multicolumn{3}{c|}{ Stage 5 - 6 } \\
\cline { 2 - 10 } & $\mathbf{n}$ & $\mathbf{z}$ & $\mathbf{d}$ & $\mathbf{x}$ & $\mathbf{z}$ & $\mathbf{d}$ & $\mathbf{x}$ & $\mathbf{z}$ & $\mathbf{d}$ \\
\hline 1 & 0,01 & $-0,22$ & 0,22 & 0,06 & 0,01 & 0,06 & 0,17 & 0,18 & 0,24 \\
\hline 2 & $-0,06$ & $-0,31$ & 0,32 & 0,06 & 0,01 & 0,07 & 0,45 & 0,20 & 0,49 \\
\hline 3 & $-0,10$ & $-0,36$ & 0,37 & 0,14 & $-0,15$ & 0,21 & 0,40 & 0,02 & 0,40 \\
\hline 4 & $-0,13$ & $-0,35$ & 0,38 & 0,11 & $-0,13$ & 0,17 & 0,29 & $-0,11$ & 0,31 \\
\hline 5 & $-0,13$ & $-0,36$ & 0,38 & 0,04 & $-0,16$ & 0,16 & 0,21 & $-0,32$ & 0,39 \\
\hline 6 & $-0,17$ & $-0,37$ & 0,41 & 0,14 & $-0,11$ & 0,17 & 0,19 & $-0,23$ & 0,30 \\
\hline 7 & $-0,10$ & $-0,39$ & 0,40 & 0,01 & 0,03 & 0,03 & 0,01 & $-0,04$ & 0,04 \\
\hline 8 & $-0,19$ & $-0,43$ & 0,47 & $-0,20$ & $-0,02$ & 0,20 & $-0,14$ & $-0,19$ & 0,23 \\
\hline 9 & $-0,13$ & $-0,38$ & 0,41 & $-0,12$ & $-0,20$ & 0,23 & $-0,08$ & $-0,30$ & 0,31 \\
\hline 10 & $-0,13$ & $-0,38$ & 0,40 & $-0,04$ & $-0,26$ & 0,26 & $-0,22$ & $-0,06$ & 0,23 \\
\hline 11 & $-0,06$ & $-0,40$ & 0,41 & $-0,05$ & $-0,13$ & 0,14 & $-0,33$ & 0,01 & 0,33 \\
\hline 12 & $-0,03$ & $-0,45$ & 0,45 & $-0,12$ & 0,12 & 0,17 & $-0,44$ & 0,06 & 0,44 \\
\hline 13 & $-0,09$ & $-0,39$ & 0,40 & $-0,11$ & 0,11 & 0,16 & $-0,19$ & 0,17 & 0,25 \\
\hline
\end{tabular}

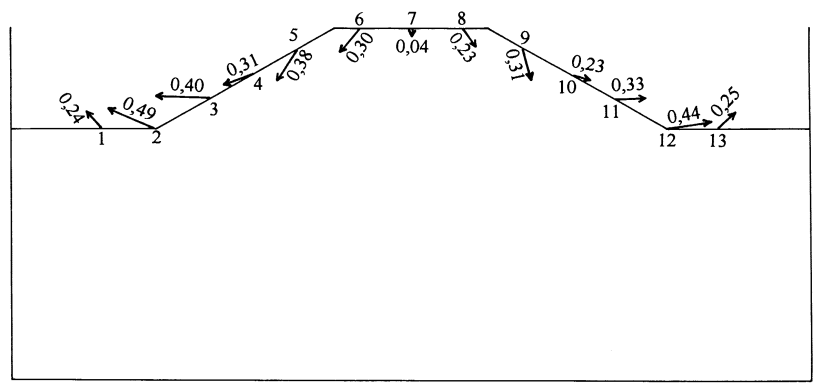

Figure 3: Model 2023 - vectors of displacements at measurement points (100x amplified).

Angle of int. friction $\varphi$

Young's modulus E

Oedometric modulus of deformation $\mathrm{E}_{\mathrm{u}}$

Coefficient of compressibility $\mathrm{C}$

Poisson's number $v$ $10^{\circ}$

$1.8 \mathrm{MPa}$

$0.5 \mathrm{MPa}$

41.3

0.25

Rocky material of the bedrock was simulated by silica sand with a prevailing grain size of $1-4 \mathrm{~mm}$, which was coated by $20 \mathrm{~mm}$ thick layer of silica sand with granularity of $0.1-0.25 \mathrm{~mm}$. This part of the model has virtually no part in 
changes to the massif due to underflooding. The body of the deposit and the bedrock to a depth of $20 \mathrm{~mm}$ below the toe of the slope were created from a mixture of fine silica sand $(80 \%)$ and bentonite $(20 \%)$. A volume swelling of $49.6 \%$ (very high swelling) is attained after a couple of tests with different equivalent material. For completeness, the dry slope and the slope with the saturated body are seen in photos figs. $4 \mathrm{a}$ and $4 \mathrm{~b}$.

In Table 2, displacements at distinct measurement points are introduced in a similar way, as in Table 1.

a)

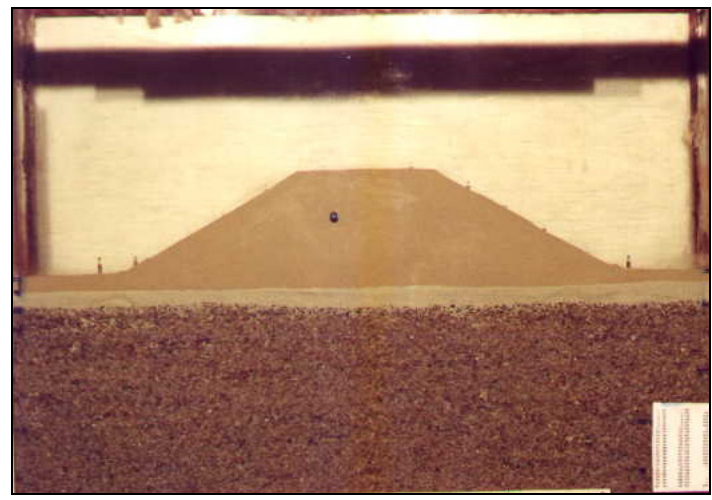

b)

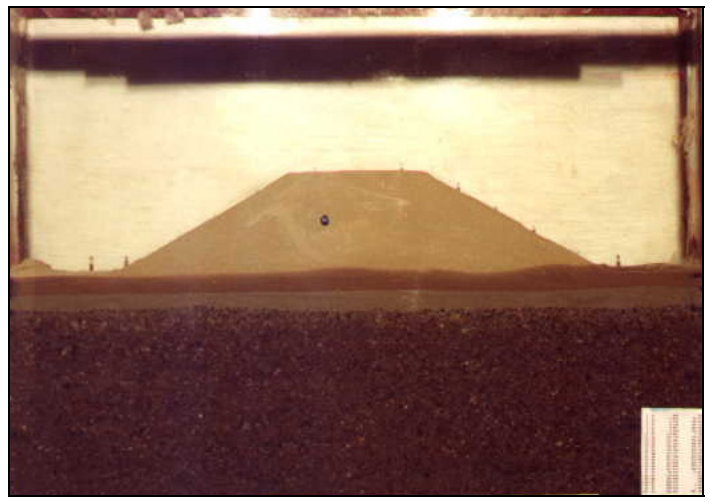

Figure 4: Photo of model 2024 before water was let in, a), and after end of the test, b).

The development of moving points can be described as: When the water level reached the toe of the slope, the process of swelling was triggered. After letting in another appropriate amount of water, the water level increased, but very slowly. The inlet was stopped and it took two days when the water level was horizontal. Letting the next amount of water into the stand, the permeability of the material had decreased due to the swelling of the equivalent materials. It took some 36 hours until the water level was horizontal again. 
In the final stage, the water rose up through the material due to capillarity. At this moment, the test was terminated. Vectors of displacements are depicted in fig. 5 .

Comparing figs. 3 and 5, in which vectors of displacements are depicted for two models 2023 and 2024 with extreme swelling properties, quite different behavior is shown. In the case of slope from material with virtually no swelling properties, the largest displacements are observed at the toe of the slope, up to about $50 \mathrm{~mm}$ in reality. Due to the strong swelling properties of the equivalent material of model 2024 and capillarity conditions, displacement upwards was ten times greater than before (fig. 5).

Table 2: $\quad$ Horizontal $\mathrm{x}$, vertical y, and resultant displacements d.

\begin{tabular}{|c|c|c|c|c|c|c|c|c|c|}
\hline \multirow{2}{*}{ Point } & \multicolumn{3}{|c|}{ Stage 1} & \multicolumn{3}{|c|}{ Stage 4} & \multicolumn{3}{|c|}{ Stage 5} \\
\hline & $\mathbf{x}$ & $\mathbf{Z}$ & d & $\mathbf{x}$ & $\mathbf{z}$ & d & $\mathbf{x}$ & $\mathbf{z}$ & d \\
\hline 1 & $-0,01$ & 0 & 0,01 & $-0,62$ & 3,26 & 3,31 & 0,10 & 0,16 & 0,19 \\
\hline 2 & 0,06 & 0,04 & 0,07 & $-0,62$ & 1,99 & 2,08 & 0,16 & 0,59 & 0,61 \\
\hline 3 & $-0,02$ & $-0,01$ & 0,03 & $-0,19$ & 0,79 & 0,82 & $-0,04$ & 0,48 & 0,48 \\
\hline 4 & $-0,06$ & 0 & 0,06 & $-0,04$ & 0,58 & 0,58 & $-0,08$ & 0,35 & 0,36 \\
\hline 5 & 0,02 & $-0,04$ & 0,05 & 0,01 & 0,45 & 0,45 & $-0,08$ & 0,36 & 0,36 \\
\hline 6 & 0,01 & 0 & 0,01 & 0,02 & 0,43 & 0,43 & 0,03 & 0,31 & 0,31 \\
\hline 7 & 0,01 & 0,05 & 0,05 & 0,01 & 0,43 & 0,43 & 0 & 0,44 & 0,44 \\
\hline 8 & 0,02 & 0,04 & 0,04 & $-0,04$ & 0,38 & 0,39 & 0,05 & 0,41 & 0,42 \\
\hline 9 & 0 & $-0,01$ & 0,01 & 0,05 & 0,41 & 0,42 & 0,02 & 0,40 & 0,41 \\
\hline 10 & 0,04 & $-0,04$ & 0,05 & 0,04 & 0,39 & 0,40 & 0,06 & 0,48 & 0,49 \\
\hline 11 & 0,06 & 0,02 & 0,07 & 0,22 & 0,63 & 0,67 & 0,04 & 0,53 & 0,53 \\
\hline 12 & 0,02 & 0,02 & 0,03 & 0,46 & 1,64 & 1,70 & $-0,12$ & 0,49 & 0,51 \\
\hline 13 & 0 & $-0,06$ & 0,06 & 0,38 & 3,36 & 3,38 & $-0,17$ & 0,29 & 0,33 \\
\hline
\end{tabular}

\section{Numerical model}

First introduce certain denotations and assumptions. Express displacements $u_{\mathrm{i}}(\xi)$ at an arbitrary point $\xi$ of the domain by virtue of superposition of displacements $\mathbf{u}^{\text {ext }}(\xi)$ at $\xi$ due to external loading applied to a linearly elastic medium, or other materials, and a linear hull of influences of, say, the eigenstresses $\lambda$, and plastic strains $\varepsilon^{\mathrm{pl}}$ at other points $\mathbf{x}$. Since we assume that at each point, two values of displacements are necessary in 2D and three values in $3 \mathrm{D}$, the relation stresses $\mathbf{u}^{\mathrm{k}}$ at the points $B_{k}, k=1, \ldots, m$, and the eigenstresses and plastic stresses $\lambda^{l}, l=1, \ldots, n$ and $\left(\sigma^{\mathrm{pl}}\right)^{l}, l=1, \ldots, m$ at $A_{l}$ becomes (to simplify the expressions, the vector notation for stress and strain tensors is used), cf. (1): 


$$
\begin{aligned}
& \left(u_{i}\right)^{k}=\left(u_{i}^{\mathrm{ext}}\right)^{k}+\sum_{j=1}^{6} \sum_{l=1}^{m}\left(T_{i j}^{\sigma}\right)^{k l},\left(\sigma_{j}^{\mathrm{rel}}\right)^{l}+\sum_{j=1}^{6} \sum_{l=1}^{m}\left(R_{i j}^{\sigma}\right)^{k l}\left(\lambda_{j}\right)^{l}, \\
& i=1, \ldots, 6, k=1, \ldots, m,
\end{aligned}
$$

or

$$
\left(u_{i}\right)^{k}=\left(S_{i}^{\sigma}\right)^{k}+\sum_{j=1}^{6} \sum_{l=1}^{n}\left(R_{i j}^{\sigma}\right)^{k l}\left(\lambda_{j}\right)^{l}, i=1, \ldots, 6, k=1, \ldots, m
$$

where $\left(S_{i}^{\sigma}\right)^{k}$ expresses the current state of the overall displacements involving nonlinear changes in the material.

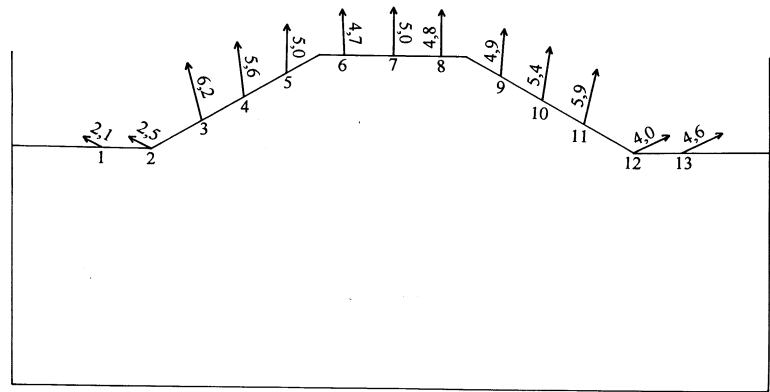

Figure 5: Model 2024 - vectors of displacement at measurement points (amplified ten times).

On the other hand, measured displacements $\left(u_{i}^{\text {meas }}\right)^{k}$ are available in a discrete set of points. A natural requirement is that the values of measured and computed values be as close as possible. This leads us to the optimization of an "error functional"

$$
I\left[\left(\lambda_{j}\right)^{l}\right]=\sum_{i=1}^{6} \sum_{k=1}^{m}\left[\left(u_{i}\right)^{k}-\left(u_{i}^{\text {meas }}\right)^{k}\right]^{2} \rightarrow \text { minimum }
$$

Differentiating $I$ by $\left(\lambda_{\alpha}\right)^{\beta}$ yields a linear system of equations for $\left(\lambda_{j}\right)^{l}$ :

$$
\sum_{j=1}^{6} \sum_{l=1}^{n}\left(A_{\alpha j}\right)^{\beta l}\left(\lambda_{j}\right)^{l}=Y_{\alpha}^{\beta}, \alpha=1, \ldots, 6, \beta=1, \ldots, \mathrm{m}
$$

where

$$
\left(A_{\alpha j}\right)^{\beta l}=\sum_{i=1}^{6} \sum_{k=1}^{m}\left(R_{i j}\right)^{k l}\left(R_{i \alpha}\right)^{k \beta}
$$




$$
Y_{\alpha}^{\beta}=-\sum_{i=1}^{6} \sum_{k=1}^{m}\left(S_{i}\right)^{k}-\left(u_{i}^{\text {meas }}\right)^{k}+\sum_{j=1}^{6} \sum_{l=1}^{m}\left(R_{i j}\right)^{k l}\left(\lambda_{j}\right)^{l}\left(R_{i \alpha}\right)^{k \beta}
$$

For more details of this procedure see [3-5].

\section{Conclusions}

In this paper, a procedure for determining mechanical behavior of earth moistened deposits from open pit mines is suggested. Information from scale models is taken into account for feeding the input data (material model) to the mathematical formulation of the physical law. Numerical codes are then tuned by an optimization problem to get as much good agreement from the results from scale and numerical models. In contrast to previous papers by the same authors, the influence of water is also considered in this study.

\section{Acknowledgment}

This paper was prepared with the financial support of GA AV ČR, project No. IAA 2119402.

\section{References}

[1] Desai Ch., Ma Y.: Modelling of joints and interfaces using the disturbed state concept - Int. J. Numer. \& Anal. Methods in Geomechanics, Vol. 16, (1995) 623-653.

[2] Trčková J., Procházka P.: Optimal material properties of slopes using coupled modelling - Proc. GEOTECH-YEAR 2000, Developments in Geotechnical Engineering, Asian Inst. of Technology, ed. A.S. Balasubramaniam et al., Bangkok, Thailand, (2000) 439-448.

[3] Trčková J., Procházka P.: Application of coupled modelling to slope stability assessment - Proc. Computational Methods and Experimental Measurements X, WIT Press, Alicante, (2001) 447-456.

[4] Procházka P., Trčková J.: Material properties of tailings of open-pit mines using coupled modeling. Proc. 5th European Conf. on Numerical methods in geotechnical engineering NUMGE 2002, Mestat (ed.), Presses de lÉNPC/LCPC, Paris, (2002a) 273-278.

[5] Procházka P., Trčková J. Material properties of tailings of open-pit mines using coupled modeling. Environmental Studies IX, series: Environmental Studies Volume 7, (2002b) 361-370. 